\title{
Conception and Gestation in Domestic Animals and Various Factors Influencing Them: A Review
}

\author{
Samuel Uchenna Felix* \\ Ahmadu Bello University, Zaria
}

Submission: May 10, 2017; Published: March 12, 2018

*Corresponding author: Felix U Samuel, Ahmadu Bello University, Zaria, Email: felixsam75@yahoo.com

\begin{abstract}
Conception and gestation are important components of the reproductive process and a hallmark of fertility. Fertility is one of the proof of worth for domestic animals. This means that biological efficiency of livestock as regard to meat, milk and wool production is conditioned by fertility. Conception occurs when the sperm fertilizes the ova. Conception rate is usually considered to be the number of dam that gives birth compared to the number of dams been serviced or exposed to the sire. Using this broad definition of conception rate, more factors can influence the results, because both fertility and embryo loss can be included in the outcome. Gestation is the time interval between fertilization of an egg and the birth of the young. It begins at fertilization and ends with parturition. Gestation lengths vary in different species. The average duration of the gestation period of domestic animals in days are as follows; mare 340, cow 283 - 284, ewe and goat 144 - 150, sow 114, bitch 58 - 63, queen 55 - 63. Many factors affect conception rates and gestation in domestic animals. Most of these factors may contribute to early pregnancy failure, abortion, still birth, mummification etc. These factors ranges from infectious to non-infectious; Viral, Bacterial, protozoa while the Non-infectious factors include but not limited to: Age, Body temperature, Usage, Genetics, Nutrition (quantity and quality) and Management (housing, Employee quality and Employee training).
\end{abstract}

Keywords: Gestation; Conception; Animals; Meat

Abbreviations: bTP: Bovine Trophoblastic Protein; oTP: Ovine Trophoblastic Protein; oIFN: Ovine Interferon's; bIFN: bovine Interferon

\section{Introduction}

Mammals are endothermic warm-blooded vertebrate animals that are distinguished by the possession of hair or fur; all female mammals nourish their young with milk, and give birth to their youngs alive. They also possess hair, three middle ear bones, mammary glands, and a neocortex which distinguished them from reptiles and birds. Examples of mammals include: humans, monkeys, cats, bats, dogs, tigers, mice, moose, elephants, gorillas, sloths, pandas, hamsters, horses, whale, and dolphins.

Three types of mammals could be distinguished and include the monotremes, which are primitive egg-laying mammals, e.g. the echidnas (spiny ant-eaters) and the duck-billed platypus. The marsupials are another group of mammals; their young are born in an extremely immature state; most female marsupials have pouches. Some marsupials include the koala, kangaroo, and the numbat. Placental mammals (eutherian) on the other hand are mammals whose young are born at a relatively advanced stage (more advanced than the young of other mammals like the monotremes and marsupials). Before birth, the young are nourished through a placenta. The placenta is a specialized embryonic organ that is attached to the mother's uterus and delivers oxygen and nutrients to the young. Most mammals are placental mammals, like cats, dogs, horses, and people (Wikipedia website).

\section{Fertilization}

Conception is a complex process and involves a series of events; it begins at a successful fertilization and implantation, and starts off gestation. The process of fertilization involves a series of specific interactions between spermatozoa and the oocyte. Spermatozoa acquire maturity during epididymal transit. However, the maturational changes that occur in the epididymis do not render spermatozoa completely fertile. For maximum fertility to be achieved, spermatozoa must reside in the female reproductive tract for a minimum period of time. During the time in the female reprofductive tract, some spermatozoa will undergo changes that allow them to become fertile. These changes are referred to as spermatozoa capacitation [1]. The site for capacitation varies among species. In species, where spermatozoa are deposited in the cranial Va $\neg$ gina, capacitation may begin as sperm ascend and pass through the cervix. In species where semen is deposited into the mid-cervix (sow) or caudal cervix, (mare) and immediately enters the uterus, 
capacitation is prob-ably initiated within the uterus and completed in the isthmus of the oviduct. All spermatozoa are not ca-pacitated at the same rate. Instead they are capacitated over a relatively long period of time; (several hours) and this reflects individual sperm differences as well as location within the tract [2]. These are outlined below.

In the oviduct the motility patterns of spermatozoa become hyperactive. The motility pattern changes from a progressive, linear motility in which they swim in a relatively straight line (like an Olympic swimmer), into a frenzied, dancing motion that is not linear and is localized in a small area (like dancers in a disco) In general, hyperactive motility occurs in the ampulla of the oviduct and is believed to be brought about by specific molecules produced by the epithelium there. Hyperactive motility is believed to facilitate sperm-oocyte contact [3]. Spermatozoa are known to contain specific proteins on their plasma membrane surfaces overlying the acrosome that bind specifically to zona pellucida proteins. These zona binding proteins on the plasma membrane must be exposed during the capacitation process before binding to the zona pellucida can occur.

The zona pellucida of the oocyte consists of three glycoproteins. These glycoproteins have been named zona proteins 1, 2 and 3 (ZP1, ZP2 and ZP3). Zona proteins 1 and 2 are structural proteins providing the structural integrity of the zona. Zona protein 3 is rnuch like a receptor for a hormone. It binds to proteins on the spermatozoal membrane. Binding of spermatozoa to the zona pellucida is believed to require between 10,000 and 50,000 ZP3 molecules.

The sperm plasma membrane contains two zona binding sites. The first binding site, referred to as the primary zona binding region is responsible for adherence of spermatozoa to the zona pellucida. The second binding site on the spermatozoal plasma membrane is believed to be acrosome T-reaction promoting ligand. When binding occurs between this region and the ZP3 molecule, a signal transduction occurs. This is much like a typical hormone receptor binding complex. Binding initiates the acrosomal reaction $[4,5]$.

Acrosomal reaction is an orderly fusion of the spermatozoal plasma membrane and the outer acrosomal membrane. The purpose of the acrosomal reaction is twofold. First, the-reaction enables spermatozoa to penetrate the zona pellucida. Second, it exposes the equatorial-segment so that it can later fuse with the plasma membrane of the oocyte.

The acrosomal reaction begins when the plasma membrane of the spermatozoon forms multiple 'fusion'sites with the outer acrosomal membrane. When the two membranes fuse, many small vesicles are formed and this process is called vesiculation. After vesiculation has occurred, the acrosomal contents are dispersed; and the sperm nucleus is left with the inner acrosomal membrane surrounding it. Vesiculation characterizes the acrosomal reaction and morphologically distinguishes it from a damaged acrosome. Damage to the acrosome membrane and plasma membrane is irreversible. Damage to these membrane is brought about by changes in osmotic pressure, sudden cooling, sudden heating or marked changes in pH. Damage to the membranes causes premature loss of acrosomal contents and such sperm cannot accomplish fertilization [6].

The penetration of the zona pellucida by a spermatozoon is believed to be a rapid process and probably takes no more than a few minutes. Following attachment to the zona pellucida, the acrosome reaction, allows the release of a variety of enzymes. Acrosin is one enzyme that is released from spermatozoa during "the acrosomal reaction. It hydrolyzes zona proteins as, well as enhances the sperm's ability to bind to the zona. In the inactive form, acrosin is known as proacrosin which has" a strong affinity for the zona. Thus, proacrosin aids in binding the spermatozoon to the zona as the acrosomal reaction proceeds. As proacrosin is converted to acrosin, the sperm begins to penetrate and make its way through the zona pellucida. The mechanical force generated by the flagellar action of the tail may be sufficient to push the sperm through the zona. It is important to note that the acrosomal reaction allows the spermatozoon to digest the zona through which it can pass. This small regional dissolution leaves the zona predominately intact.

When the spermatozoon completely penetrates the zona and reaches the perivitelline space (the space between the zona and the oocyte plasma membrane), it settles into a bed of microvilli formed from the oocyte plasma membrane. The plasma membrane of the oocyte fuses with the membrane of the equatorial segment and the fertilizing spermatozoon is engulfed. The actual fusion of the oocyte plasma membrane with the equatorial segment is believed to be brought about by a socalled fusion protein located on this portion of the membrane. Prior to the acrosome reaction, this fusion protein is inactive. After vesiculation and release of the acrosomal contents, the fusion protein is activated, enabling the sperm membrane to fuse or bind with the oocyte membrane.

After membrane fusion, the oocyte undergoes a series of changes that prepare it for early embryogenesis. The most easily recognizable is the cortical reaction, during the first and second meiotic divisions of oogenesis, small, dense granules called cortical granules move to the periphery of the oocyte cytoplasm. The contents of the cortical granules consist of muco-polysaccharides., proteases, plasminogen activator, acid phosphatase and peroxidase. After membrane fusion between the oocyte and spermatozoon, the cortical granules undergo exocytosis and their contents are released into the perivitelline space as shown above. Exo- cytosis of the cortical granules results in the zona block, a process whereby the zona pellucida undergoes biochemical changes so that further sperm cannot penetrate it. There by preventing polyspermy (fertilization of an oocyte by more than one spermatozoon which results in embryo death) [6] (Figure 1). 
The plasma membrane of egididymal spermatozea con: tains a complement of surface molecules (probeins and carbohydrates) ibus. trated here as yel. low Ts.

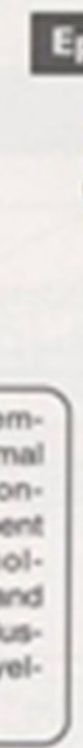

Epididymal
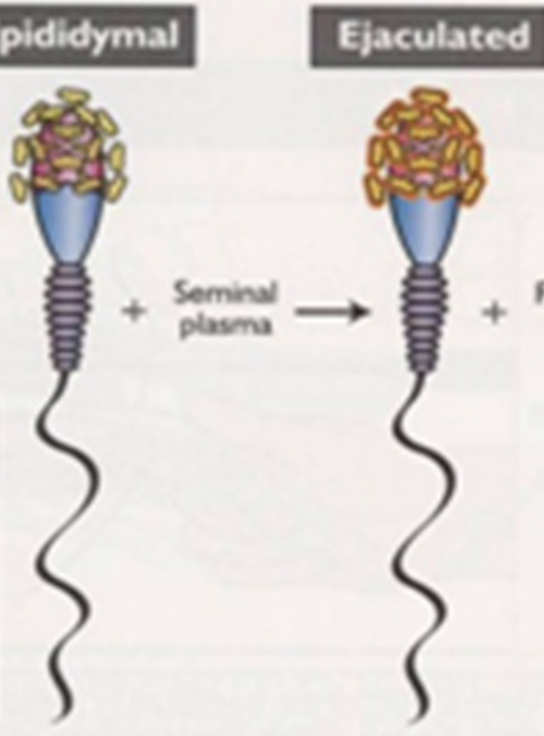

Semina
plasma
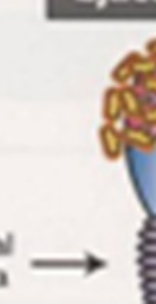

The surtace molecules in epididymal sperm become

coased with seminal plasma proteins (orange halos)

that mask portions of the membrane molecules.

Figure 1: Conceptual version of mammalian capacitation.

\section{Conception}

Conception is the point in time when the sperm fertilizes the ova. Conception rate is usually considered to be the number of dam that give birth compared to the number of dams been serviced or exposed to the sire. Using this broad definition of conception rate, more factors can influence the results, because both fertility and embryo loss can be included in the outcome.

\section{The conceptus}

The terms embryo, conceptus and fetus are often used interchangeably to describe the developing organism [6].The embryo or fetus together with the tissues, such as the placenta, that nourishes it is refered to as the Conceptus [7].

A conceptus can also be defined as the product of conception \& it includes:

a. The embryo during the early embryonic stage.

b. The embryo and extra embryonic membranes during the pre-implantation stage.

c. The fetus and placenta during the post-attachment phase.

After fertilization, four important developmental events must occur before the embryo attaches to the uterus, only after these milestones are achieved will the embryo be eligible to develop a more intimate, semi-permanent relationship with the uterus.

a. Development within the confines of the zona pellucid. b. Hatching of the blastocyst from the zona pellucid.

c. Maternal recognition of pregnancy.

d. Formation of the extraembryonic membranes.

\section{Mechanism of conception}

Following fusion of the male and female pronuclei, the single-celled embryo, now called a zygote, undergoes a series of mitotic divisions called cleavage divisions. The first cleavage division generates a two celled embryo, the cells of whichare called blastomeres. Each blastomere in the two-celled embryo is about the same size and represents almost exactly one half of the single-celled zygote. Each blastomere undergoes subsequent divisions, yielding 4, 8 and then 16 daughter cells. When a solid ball of cells is formed and individual blastomeres can no longer be counted accurately, the early embryo is called a morula.

When the morula is formed, the outer cells begin to be compacted more than the cells in the center. Thus, during the morula stage, cells begin to separate into two distinct populations, the inner and outer cells; Cells in the inner portion of the morula develop gap junctions that allow for intercellular communication and may enable the inner cells, to remain in a defined cluster. The outer cells of the morula develop cell-to-cell adhesions known as tight junctions. These tight junctions are believed to alter the permeability of the outer cells. After the tight junctions are formed, fluid begins to accumulate inside the embryo. This fluid accumulation is believed to be brought about by an active sodium pump in the outer cells of the morula that pump sodium 
ions into the center portion of the morula. This buildup of ions causes the ionic concentration of 'the fluid surrounding the inner cells of the morula to increase. As the ionic strength inside the morula increases, water diffuses through the zona pellucida into the embryo and begins to form a fluid filled cavity called a blastocoele. When a distinct cavity is recognizable, the embryo is called a blastocyst. Because of the nature of the tight junctions (found in the outer cells) and the gap junctions (found among the inner cells), the embryo becomes partitioned into two distinct cellular populations. These are known as the inner cell mass and the tropho blast. The inner cell mass will give rise to the body of the embryo. The trophoblastic cells will eventually give rise to the chorion (which forms the fetal component of the placenta). Concurrent with growth of the blastocyst and fluid accumulation in the blastocoele is the production of proteolytic enzymes by the trophoblastic cells. These enzymes weaken the zona pellucida so that it ruptures easily as growth of the blastocyst continues. Finally, the blastocyst itself begins to contract and relax causing intermittent pressure pulses. These pressure pulses coupled with continued growth and enzymatic degradation cause the zona pellucida to rupture. The blastocyst upon hatching from the zona pellucida becomes a free floating embryo within the lumen of the uterus and is totally dependent on the uterine environment for survival.

After hatching, the conceptus undergoes massive growth. In the cow at day 13 the blastocyst is about $3 \mathrm{~mm}$ in diameter. During the next four days, the cow blastocyst will become $250 \mathrm{~mm}$ in length (about the vertical length of the printed portion of this page) and will appear as a filamentous thread. By day 18 of gestation, the blastocyst occupies space in both uterine horns. While the blastocyst of the cow (and the ewe) grows quite rapidly during this early pre-attachment stage, the development of the pig blastocyst is even more dramatic. On day 10 of pregnancy, pig blastocysts are $2 \mathrm{~mm}$ spheres. During the next 24 to 48 hours, these $2 \mathrm{~mm}$ blastocysts will grow to about $200 \mathrm{~mm}$ in length. This means that the blastocyst is growing at a rate of 4 to $8 \mathrm{~mm}$ per hour, by day 16, the pig blastocyst reaches lengths of 800 to $1000 \mathrm{~mm}$. The dramatic growth of the conceptus is due largely to the development of a set of membranes called the extraembryonic membranes. The pig, sheep and cow are characterized as having filamentous or threadlike blastocysts prior to attachment. In the mare, however, blastocysts do not change into a threadlike structure but remain spherical.

Formation of the extra embryonic membranes is an obligatory step in the acquisition of the embryo's ability to attach to the uterus of the dam. The extra embryonic membranes are a set of four anatomically distinct membranes; the chorion and amnion, which develops from the trophoblast, primitive endoderm and mesoderm; the yolk sac forms from the primitive endoderm and the allantois forms as a small evagination from the primitive gut of the embryo; as the embryo grows the allantois expands and eventually makes contact with the chorion, fusing with it to form the allantochorion. The allantochorionic membrane is the fetal contribution to the placenta and will provide the surface for attachments to the endometrium.

\section{Maternal Recognition of Pregnancy}

Maternal recognition of pregnancy refers to the critical series of events by which the conceptus initially signals its presence to the dam and enables pregnancy to continue. In order for the events of early embryogenesis to continue into an established pregnancy, luteolysis must be prevented by the maintenance of progesterone at a sufficiently high levels; as such embryogenesis and attachment of the developing conceptus to the endometrium can take place.

If an adequate sig $\neg$ nal is not delivered in a timely manner, the dam will experience luteolysis, progesterone concentrations will decline and pregnancy will be terminated. The table below shows recognition factors as they relate to the critical recognition period in different species (Table 1).

Table 1: Pregnancy recognition factors, critical days of pregnancy recognition and time of conceptus attachment in mammals.

\begin{tabular}{|c|c|c|c|}
\hline Species & $\begin{array}{c}\text { Pregnancy } \\
\text { Recognition } \\
\text { Factors }\end{array}$ & $\begin{array}{c}\text { Critical } \\
\text { Period for } \\
\text { Recognition } \\
\text { (days after } \\
\text { ovulation) }\end{array}$ & $\begin{array}{c}\text { Critical } \\
\text { Period for } \\
\text { Recognition } \\
\text { (days after } \\
\text { ovulation) }\end{array}$ \\
\hline Bitch & none needed & - & - \\
\hline Cow & bIFN- $\tau$ (bTP-1) & $15-16$ & $18-22$ \\
\hline Ewe & oIFN- $\tau$ (oTP-1) & $13-14$ & $15-18$ \\
\hline Mare & $\begin{array}{c}3 \text { Proteins/ } \\
\text { Estrogens=? }\end{array}$ & $12-14$ & $36-38$ \\
\hline Queen & none needed & - & - \\
\hline Sow & Estradiol(E2 $\neg)$ & $11-12$ & $14-18$ \\
\hline Woman & hCG & $7-12$ & $9-12$ \\
\hline
\end{tabular}

(Adapted from Senger, P.L. 2005)

\section{Mechanism of Maternal Recognition of Pregnancy}

\section{Cow and ewe}

In the ewe and the cow the free-floating blastocyst produces specific proteins that provide the signal for prevention of luteolysis. The specific proteins were once called ovine trophoblastic protein 1 (oTP-1) and bovine trophoblastic protein 1 (bTP-1). Both of these proteins belong to a class of materials known as interferons. Most interferons are nonspecific glycoproteins produced by leukocytes, fibroblasts, lymphocytes and trophoblastic cells. Interferons have antiviral action and alter the function of target cells. Because trophoblastic protein (oTP-l and bTP-1) constitute a separate class of interferons; they are now referred to as ovine Interferon's (oIFN-T) and bovine Interferon T (bIFN-T) (Table 2). 
Table 2: Periods of Gestation.

\begin{tabular}{|c|c|c|c|c|}
\hline \multirow{2}{*}{ Animals } & \multicolumn{2}{|c|}{ Average Period } & \multirow{2}{*}{$\begin{array}{c}\text { Shortest } \\
\text { Period Young } \\
\text { Born Alive }\end{array}$} & \multirow{2}{*}{$\begin{array}{c}\text { Longest } \\
\text { Period } \\
\text { Young } \\
\text { Born } \\
\text { Alive }\end{array}$} \\
\hline & \multicolumn{2}{|c|}{$\begin{array}{c}\text { Months } \\
\text { Days }\end{array}$} & & \\
\hline Mare & 11 & 340 & 340 & \\
\hline Cow & 9 & 283 or 284 & 200 & 414 \\
\hline $\begin{array}{c}\text { Ewe and } \\
\text { goat }\end{array}$ & $\begin{array}{l}5 \\
-\end{array}$ & $\begin{array}{c}144 \text { to } 150 \\
(150)\end{array}$ & 135 & 439 \\
\hline Sow & - & 114 & 110 & 130 \\
\hline Bitch & - & $58-63$ & 55 & 76 \\
\hline Cat & & $55-63$ & - & \\
\hline
\end{tabular}

(Adapted from the blacks Veterinary dictionary)

A relatively small protein (18,000 to 20,000 daltons), oIFN-T is produced by the trophoblastic cells of the blastocyst and is present in the uterus from about day 13 to 21 after ovulation. Production of progesterone by the corpus luteum cannot be enhanced by oIFN-T and therefore it is not luteotrophic. Instead, oIFN-T binds to the endometrium and inhibits oxytocin receptor synthesis by endometrial cells. In addition to blocking oxytocin receptor synthesis, IFN-T also binds to the apical portion of the uterine glands and promotes protein synthesis believed to be critical to preimplantation embryonic survival.

\section{Sow}

In the sow, two major differences exist in maternal recognition of pregnancy, compared to the ewe and cow. First, the conceptus of the pig produces estradiol that serves as the signal for maternal recognition of pregnancy. Second, PGF $2 \alpha$ is produced in significant quantities, but is rerouted into the uterine lumen. The conceptus begins to produce estradiol between days 11 and 12 after ovulation. The production of estrogen does not inhibit the production of PGF $2 \alpha$ but causes the PGF $2 \alpha$ to be secreted in a different direction than in the cycling sow. The direction of secretion is away from the submucosal capillaries and toward the uterine lumen; Luminal PGF2 $\alpha$ has little access to the circulation and thus cannot cause luteolysis. The precise, mechanism whereby the rerouting of PGF $2 \alpha$ occurs is not completely understood. However, it is believed that estrogen causes increased receptor production for prolactin in the endometrium. Prolactin changes the ionic flux for calcium. This is thought to promote the exocrine secretion of PGF2 $\alpha$ (into the uterine lumen) rather than an endocrine secretion (into the uterine vasculature). Porcine conceptuses produce interferons, but these materials do not affect corpora lutea longevity or function. Production E2 by the porcine conceptus not only serves as the maternal signal to prevent luteolysis, but also probably serves to stimulate contractions of the myometrium to distribute conceptuses with the proper spacing along the uterine horn.

Another important feature of maternal recognition of pregnancy in the sow is that there must be at least two conceptuses present in each uterine horn for pregnancy to be maintained. If conceptuses are not present in one uterine horn, PGF2 $\alpha$ will be secreted in an endocrine fashion, luteolysis will occur and the pregnancy will be terminated.

\section{Mare}

In the mare, the presence of the conceptus prevents luteolysis. Also, in the presence of the conceptus, endometrial production of PGF $2 \alpha$ is significantly reduced. A unique feature of maternal recognition of pregnancy in the mare is that the conceptus must migrate within the uterus from one uterine horn to the other. This migration must occur between 12 and 14 times per day during days 12,13 and 14 of pregnancy in order to inhibit PGF2 $\alpha$. The intrauterine migration of the equine conceptus appears necessary because the conceptus does not elongate as in other species. Therefore, there is less contact between the conceptus and the endometrial surface. In other words, the migration of the conceptus is probably necessary to distribute pregnancy recognition factors to the endometrial cells. Like the other species, the conceptus of the horse produces proteins that apparently have some effect on the recognition of pregnancy. However, the specific roles are yet unknown.

\section{Humans}

At about the time of implantation (day 7-9 after ovulation) the human conceptus begins to secrete a hormone called human chorionic gonadotropin (hCG). This is an LH-like hormone that acts on the corpus luteum to inhibit intraovarian luteolysis. The precise mechanism whereby hCG blocks luteolysis is not known; Regardless, the luteotrophic effect of hCG is sufficient to allow for implantation and maintenance of pregnancy.

\section{Dogs and cats}

In the bitch, the Corpus luteum of pregnancy and the Corpus luteum of the Corpus luteum have similar lifespans. Therefore, under normal cyclic conditions, the Corpus luteum is long-lived. When luteolysis does occur it is near the end of the normal gestation period. In other words, the period of diestrus is quite similar to the gestation period and thus, the corpus luteum is not lysed under normal conditions until the gestation period is complete.

The queen is an induced ovulator. If mating does not occur, corpora lutea are not formed and a "post estrous" period of several days (8-10) exists before another estrus. In the queen that has been bred, a Corpus luteum forms and the duration is the same as gestation (about 60 days). Like the bitch, a signal from the conceptus is not needed because corpora lutea are not lysed before a pregnancy is established.

\section{Gestation}

Gestation is the time interval between fertilization of an egg and the birth of the young. It begins at fertilization and ends with parturition. Gestation lengths vary in different species. Gestation costs about 3\% of the daily energy requirement 
during the first 3 months and $20 \%$ during the last 2 months. The uterus, the ovaries, and the whole of the tissues of the mother are influenced directly or indirectly during pregnancy, but the gross changes exhibited, with certain exceptions, subside quickly after the birth of the young. The minor alterations which persist throughout life, such as increased size of the mammary glands, enlargement of the uterus, and of the whole of the genital canal, are not generally obvious except after repeated breeding, and in from 4 to 6 weeks the dam has returned to normal to all intents and purposes, always excepting the flow of milk in the mammary glands.

There are three stages (trimesters) of pregnancy in the bitch. The first stage begins with fertilization and ends when the embryos implant in the uterus (approximately 20-22 days after the LH surge); the second stage begins at implantation and ends when the fetuses undergo ossification (40-42 days following the LH surge); the final stage begins at fetal ossification and ends at whelping.

\section{Factors Affecting Conception and Gestation}

Many factors affect conception rates and gestation in domestic animals. Most of these factors may contribute to early pregnancy failure, including factors intrinsic to the conceptus, factors intrinsic to the dam, extrinsic factors, and combinations of all of these factors causing conception and gestation problems. The gestation period is a period of development and there is a continuous process of tissue differentiation, organogenesis and maturation. The process is complex, and critical periods of development occur at different times in the different species. Agents causing embryonic loss are therefore highly variable [8].

\section{Nutrition}

\section{In the ewe and doe}

In particular, nutrition is one of the main factors affecting ovulation rate. It is important to get the nutrition right to prevent loss of body condition or problems at lambing. The beneficial effects of nutrition on reproduction in sheep are well known [9].

Poor nutrition may cause irregular cycles in females, reduced ovulation, weak offspring, and pregnancy toxemia or reduced twinning. Under-nutrition in late gestation leads to a decrease in birth weight and lowers lamb or kid survival. Although undernutrition is the most common cause of reproductive failure, overfeeding during late gestation should be avoided as it can increase the occurrence of dystocia (difficulty in giving birth). In the long term, unbalanced nutrition during pregnancy has a consequence on the fertility of the offspring [10-13]. Flushing is understood as the rapid increase in ovulation rate of ewes receiving a nutrient supplementation before mating [14].

\section{In cow}

Early onset of cycling clearly increases submission rates and conception rates. Negative energy balance long before insemination may reduce conception rate; in the ovary adverse condition around estrus can result in a defective egg being produced and released. If true, then severe weight loss in early lactation could result in poor quality egg production. Fertility of the cows decline when their body condition score (BCS) drops to below 4; especially at calving and when they go into breeding season in poor condition [15].

\section{Infections}

Some infectious agents, such as bacteria, viruses, fungi and mycoplasma are also known to interfere with reproduction. Bacterial infections of the uterus, vagina and vestibulae can lead to anestrus, repeat breeding, delayed return to oestrus after mating, early embryonic death and, sometimes, abortion. Endometritis, placentitis and vaginitis are chief among inflammatory reproductive tract infections in domestic animals [16].=

In cows: The important diseases which are responsible for infertility and abortion in livestock are brucellosis, infectious bovine rhinotracheitis, leptospirosis, listeriosis, salmonellosis, chlamydiosis ,campylobacteriosis, trichomoniasis, epizootic bovine abortion, mycotic abortion, corynebacteriosis, neosporosis, foot and mouth disease, etc. Brucella abortus- the pathogen which causes brucellosis has an affinity for uterus resulting in abortion. In trichomoniasis, abortion occurs in the early pregnancy. Leptospira pomona leads to abortion in 6 months to full term of pregnancy. In listeriosis, abortion takes place at approximately 7 months of pregnancy. Infectious bovine rhinotracheitis virus affects reproductive system as well as respiratory system. Abortion has been reported in lambs due to foot and mouth disease virus. The foundation of an accurate diagnosis of reproductive loss due to infectious pathogens facilitates prudent use of immunization and biosecurity to minimize reproductive losses. However, nearly half of the cows are still capable of breeding, indicating that pathological conditions do not necessarily render cows permanently sterile. Their seriousness depends on the location of the infection. Many diseases can be substantially reduced by vaccinations. Infected animals may require to be eliminated to prevent spread of infection. Pathological causes due to infectious diseases are responsible for about $25 \%$ of cases [15].

In sows: Brucella abortus, Brucella melitensis and Brucella suis are chief among bacteria infectious diseases prevalent in the sow; Infertility, irregular estrus, small litters,and abortion occur. Mummification andstillbirths do occur. The incidence of abortionvaries widely between herds but isusually low and is usually early on. Catastrophic outbreak of abortions, stillborns, and mummies are associated with viral infections, PRRSv infections, porcine circovirus (PCV-2), swine influenza, and consequences of PEDv outbreaks $[17,18]$. Parvovirus is the most prevalent viral agent involved with infertility. It rarely causes repeat breeding alone but often results in mummification of fetuses. It occurs much more frequently in gilts than sows [19]. 


\section{In bitches}

Infections of the vagina or uterus can prevent conception and prevent the bitch from carrying her litter to term. Vaginal infections (vaginitis) are most frequently caused by bacterial microorganisms, especially by Brucella canis. Brucellosis is a venereal disease that causes infertility by either preventing conception or causing spontaneous abortion. Contrary to popular belief, the infectious microorganism, Brucella canis, can be transmitted sexually or orally with equal frequency and has the potential to infect people. Infection with the canine herpesvirus can also lead to infertility. Uterine infections can contribute to infertility, such as endometritis, pyometra/pyometritis and metritis.

\section{In mares}

Fungal endometritis: The most common fungi in fungal endometritis in horses include the Candida (yeast) and Aspergillus (mold) - that proliferate when the natural immune system has been weakened after antibiotic use.

Bacterial endometritis: Bacterial endometritis may be the most common complaint in infertile mares. It is one of the major reasons that mares don't settle, or conceive but then slip the foal. It is probably also the main cause of infertility in older mares who have foaled before. Acute infectious endometritis may be the result of impairment of the normal uterine defense systems, which may break down over time. In a related problem, weakened reproductive structures may cause urine pooling, a condition in which mares do not void urine completely, particularly during estrus. The retained fluid can cause inflammation, and prevent conception.

Placentitis: Placentitis is an infection of the placenta; it may be introduced through the shared blood supply or may work its way from the cervix into the uterus. In this condition, the mare manages to get in foal, but the foal is aborted. a majority of foals lost in late term pregnancy may be attributable to placentitis.

\section{Viral infections}

Equine arteritis virus (EAV) infection: it is known to affect reproduction in mares and stallions, causing abortion after the third month of pregnancy or the death of foals after birth.

Contagious Equine Metritis (CEM): this is a venereal disease of horses caused by the bacterium Taylorella equigenitalis, which is carried by stallions and causes infertility or abortion in mares.

\section{Anatomical or Structural Congenital Defects}

\section{In bitches}

The most common are congenital strictures or constrictions inside the vaginal canal, and benign or malignant tumors, both of which can physically prevent successful mating and movement of sperm from the vagina through the cervix and into the uterus. Strictures often make mating painful or impossible and can make both the bitch and the stud dog reluctant to try to consummate the union. Blockage of the oviducts with tumors or masses can prevent ovulated eggs from successfully uniting with sperm.

Ovarian abnormalities are common anatomical causes of infertility in dogs. They include ovarian cysts and tumors, which can cause prolonged heat cycles or shortened intervals between cycles. Cystic uterine endometrial hyperplasia is another common anatomical cause of infertility. Bitches that have previously been spayed (have had an ovariohysterectomy) obviously have legitimate anatomical reasons for their infertility. Bitches with intersex disorders (hermaphroditism; pseudo hermaphroditism; others) have a poor chance of successfully reproducing. Fortunately, intersex disorders are very uncommon in dogs.

\section{In mares}

Cervical incompetence, or 'Maiden Cervix': A mare that hasn't been bred before may have a problem called "maiden cervix", in which the cervix so tightly closed that the excess seminal fluids can't be properly drained away after mating. Fluid that is retained causes inflammation and, if untreated, creates an acidic environment which soon becomes an infection.

Pneumovagina: This is an oddly shaped vulva, which doesn't seal properly, exposing the uterus to contamination. With this Poor vulvar conformation air is pulled into the vagina, along with bacteria. It can also result in fecal bacteria moving into the vaginal area. The bacteria proliferate, infection sets in, and what started out as a mechanical problem can become a long-standing infectious ailment that renders mares infertile.

\section{Hormonal Factors}

\section{In bitches and queens}

Hormonal influences are among the most important reasons for infertility in domestic dogs and cats. Hormones are chemical substances produced by various glands in the body, such as the adrenal glands, pancreas, pituitary and thyroid.

\section{Hypothyroidism}

Hypothyroidism is the most common hormonal cause of infertility in the bitch; it is a low circulating levels of thyroid hormones. The thyroid gland is located in the neck and secretes hormones that are essential for a multitude of body functions. Low levels of thyroid hormones can lead to lack of sex drive (libido) and infertility.

\section{Adrenal dysfunction or insufficiency}

Adrenal Dysfunction or insufficiency can interfere with the production of sex hormones that are necessary for proper reproductive function. The adrenal glands are paired structures located just above each kidney. They normally produce a number of important steroid hormones. Two common adrenal disorders in domestic dogs, Cushing's disease (hyperadrenocorticism) and Addison's Disease (hypoadrenocorticism), usually prevent female dogs from conceiving and carrying a litter to term. 


\section{The tiny pituitary gland}

The tiny pituitary gland located deep in the brain, is critically involved in producing and releasing hormones that start and regulate the estrous cycle. Any disease or disorder of the pituitary can cause canine infertility due to abnormal heat cycling. This can include failure to ovulate, abnormal ovulation pattern or timing, persistent heat cycle, primary congenital anestrus (never having a heat cycle), split heat, silent heat and false pregnancy/ pseudo pregnancy.

Fertility is determined by a multi-hormonal effect, not only including sex and gonadotropic hormones, but also "metabolic" hormones. A functional defect in any of the components of this hormonal complex directly affects reproduction [20].

\section{Age}

\section{In mares}

There is a significant decrease in live foaling rates as mare age increases, but not as stallion age increases. There is a logical biological reason for this difference between mares and stallions. In mares, all of the eggs that she will ever have in her lifetime are formed when she herself is a fetus. Therefore, by the time a mare is 20 years old, her eggs are 20 years old. Aging of the oocytes is a very important factor in the decreased ability to produce live offspring as females age. The same thing happens in women. In stallions, sperm are continually being formed. Therefore stallion aging does not affect sperm competence the way that mare aging affects oocyte competence.

\section{Drugs and Medications}

\section{In bitches and queens}

Dietary supplementation of the pregnant bitches' usual food with vitamins and other minerals is a practice that should be discouraged by veterinarians now. It is recognized that many vitamins and minerals may actually be harmful to the developing fetuses or produce serious pregnancy-related complications in the bitch. For example, excess vitamin A is associated with congenital defects such as cleft palate, and vitamin D may compromise the calcium mobilization within the bitch. Excess vitamin C may interfere with normal processes of bone development, and because dogs produce sufficient amounts of this vitamin, supplementation with vitamin $\mathrm{C}$ is simply unnecessary. Excessive levels of calcium in the body, which usually occurs when a bitch is supplemented with calcium above the amount found in a high-quality dog food, interferes with the normal processes of calcium storage and metabolism by suppressing parathyroid hormone production. Ironically, therefore, calcium supplementation actually has the opposite effect of its intended purpose because excess calcium interferes with calcium storage and places the bitch at risk for developing hypocalcemia (pre-eclampsia or eclampsia), an often fatal metabolic disorder caused by insufficient calcium availability in pregnant and nursing bitches, respectively.
Administration of any type of medication is not recommended between days 13 and 30 of the pregnancy. When administration of medication is warranted during any point in the pregnancy, the risk to benefits should be carefully weighed. Though some drugs have been deemed as relatively safe for use during pregnancy, others have been found to be dangerous, and effects of some others on pregnancy and the developing fetuses are still unknown.

\section{Genetic Factors}

Genetics/heredity affects the fertility of farm animals in a variety of ways. Some animals are genetically infertile. Genetic factors causing embryonic loss include single-gene defects, polygenic abnormalities and chromosomal anomalies. A few single-gene mutations are lethal and result in the death of the conceptus [8].

\section{In bitches}

Genetic factors contribute to embryonic defects and fetal malformation. These, in turn, can lead to mummified, reabsorbed or aborted puppies.

\section{In does and ewe}

Genetic differences do exist between different breed and types of sheep and goat. Genetic mutations can occur which can produce infertility. They can also give rise to abnormal development in embryos so much so that the young fail to develop properly and cause fetal death or atrophy. These are called lethal factors.

\section{Management and Environment}

By far the most common cause of infertility in domestic dogs is improper breeding management. This includes failing to properly detect and assess the progress of the bitch's heat (estrus) cycle, insemination at the wrong time and miscalculating the appropriate number of breeding to be accomplished per estrus cycle. Silent heats, split heats, abnormally long heats, missed heats and irregular heats all occur in female dogs and can contribute to breeding management timing errors.

Noise, crowding, poor hygiene/sanitation, psychological factors, temperature extremes and exposure to inclement weather), stress, external and internal parasite management programs. Psychological factors can be important contributors to canine infertility. For example, many bitches raised exclusively as house pets are shy breeders, because they have not had much social contact with other dogs. Some males are extremely aggressive during mating, which can traumatize the bitch and create an unpleasant, fearful association with sexual activity. Close inbreeding can also interfere with normal fertility in subsequent generations.

\section{In cow}

Failure to detect oestrus and time of onset of oestrus in buffalo considerable percentage of oestrus cycles are left uncovered 
resulting in increase of unproductive period which adversely affect economics of livestock production [15].

\section{In ewe and doe}

The farm manager has the ability to control or at least to manipulate the factors that have been discussed above. Different ewe farms have different management practices and this may have an impact on fertility. Examples of how farmers control or manipulate these factors include:

a. Selection of both male and female animals on the basis of their ability to produce offspring.

b. Ensuring the correct proportion of male to female animals if using naturalmating.

c. Selecting animals suited to the environment

d. Providing correct nutrition for the stage of production of the animals

e. Selecting paddocks that minimize the detrimental effects of environmental factors for newly born animals

f. Use of strategic worm control program

g. Use of a suitable vaccination program $[21,22]$.

\section{Overuse of the Male}

Too much stress or overuse of a stallion, bull, ram, buck, boar and dog can lead to infertility or psychological problems that may interfere with their sex drive. Too frequent breeding or collecting can cause male animals to lose their libido, making breeding and collecting more difficult and lowering the overall quality of collected semen; lactation which leads to late return to cyclicity. Dogs with frequent sexual usage and low quality semen may regain fertility when used sparingly to allow spermatozoa to accumulate in the epididymis (Feldman and Nelson, 1996) [2327].

Boars used excessively (more than 7 matings per week) on a continual basis may have reduced fertility. Therefore, boars should be rotated every 24 hours during heavy pen mating usage ( 2 boars for every 4 to 6 sows weaned per week.

\section{References}

1. Anderson GB (1991) Fertilization early development and embryo transfer in Reproduction in Domestic Animals. In: PT Cupps (Ed.), $\left(4^{\text {th }}\right.$ edn), Academic ss, New York, USA.

2. Crozct N, Man C, Thibault MC, Levasseur RH (1993) Fertilization in-vivo and in-vitro in Reproduction in Mammals, Ellipses, Paris, France.

3. Yanagimaehi R, Knobil E (1996) Mammalian fertilization in hysinlogy of Reproduction. (2 $2^{\text {nd }}$ edn), Raven Press, New York, USA, 1: 189-318.

4. Saacke KJ, Viillins JS (1989) Study of the functional anatomy of bovine cervical mucosa with social reference to mucus secretion and sperm trans $\urcorner$ port. Anat Rec 225: 106-117.

5. Senger PL, Pullmann (2005) conceptions inc. Washington state university Research and technology park, 1610 NE Northeast gate Blvd, Pathways to pregnancy and parturition, $\left(2^{\text {nd }} e d n\right)$, Current,
6. Blood DC (2006) Veterinary Medicine, A Textbook of the Diseases of Cattle, Sheep, Goats, Pigs and Horses. $\left(10^{\text {th }}\right.$ edn), Elsevier , Edinburgh London New York, St Louis Sydney Toronto, Oxford Philadelphia, Pennsylvania.

7. Noakes DE, Parkin On, TJ Edmon, GC W (2001) Arthur's Veterinarv Reproduction and Obstetrics ( $8^{\text {th }}$ edn). England.

8. Forcada F and Abecia JA (2006) The effect of nutrition on the seasonality of reproduction in ewes. Reprod Nutr Dev 46: 355-365.

9. Galloway SM, Mcnatty KP, Cambridge LM (2000) Mutations in anoocyte-derived growth differentiation factor gene (BMP15) cause increased ovulation rate and infertility in a dosage-sensitive manner. Nature Genetics 25: 279-283.

10. Davis GH, Dodds KG (2001) Evidence that an imprinted gene on the $\mathrm{X}$ chromosome increases ovulation rate in sheep Biology of Reproduction 64: 216-221.

11. Wilson T, Xi-Yang W, Juengel Jl, Ross IK, Lumsden JM, et al. (2001) Highly prolific booroola Sheep have a mutation in the intracellular kinase domain of bone morphogenetic Protein receptor (alk- 6) that is expressed in both oocytes and granulosa cells. Biol Reprod 64: 12251235.

12. Branca A, Molle G, Sitzia M, Decandia M, Landau S (2000) Short-term dietary effects on reproductive wastage after induced ovulation and body weights and carcass yields in karayaka sheep. Asian J Anim, Vet Adv 5: 120-127.

13. NAAS (2013) Livestock Infertility and Its Management. Policy Paper No. 59, National Academy of Agricultural Sciences, New Delhi, India p. 20.

14. Prakash BS (2011) Summer infertility in buffaloes: Problems and Prospects of Improvement using endocrine techniques. Proceedings of the Advanced Training Course on Advances in Applications of Diagnostic Techniques in Veterinary Theriogenology, Centre of Advanced Training in Veterinary Gynaecology and Reproduction, GADVASU, Ludhiana p. 30-38.

15. Pittman JS (2008) Reproductive failure associated with porcine circovirus type 2 in gilts. J Swine Health \& Production 16:144-148.

16. Almond GW (2014) Challenges associated with reproductive failure in sows. Proceedings of the London Swine Conference, London, UK, p. 50-54.

17. Lawrence E, Jack B, Clyde K, Don L (2008) Troubleshooting Swine Reproduction Failure. PIG 08-07-01.

18. Abadjieva D, Shumkov K, Kistanova E, Kacheva D, Georgiev B (2011) Opportunities for the Improvement of the Reproductive Performances in Female Animals .Biotechnology in Animal Husbandry 27: 365-372.

19. Anel l, Kaabi M, Abroug B, Alvarez, M, Anel, et al. (2005) factors influencing the success of vaginal Anoocyte-derived growth differentiation factor gene (bmp15) cause increased Ovulation rate and infertility in a dosage-sensitive manner. Nature genetics 25: 279-283.

20. Paulenz H, Adnoy T, Fossen OH, Soderquist L, Berg KA (2002) Effect of deposition site and sperm number on the fertility of sheep inseminated with liquid semen. Veterinary Record 150(10): 299 -302.

21. Aliyari D, Moeini MM, Shahir MH, Sirjani MA (2012) Effect of Body Condition Score, Live Weight and Age on Reproductive Performance of Afshari Ewes. Asian Journal of Animal and Veterinary Advances 7: 904-909.

22. Al-Shorepy SA, Notter dR (1997) Response to Selection for Fertility in a Fall-Lambing Sheep Flock. J Anim Sci 75: 2033-2040.

23. Behrendt-Adam, Adams CY, Simpson MH, Mc Dowell KC (1999) Oxytocin-neurophysin I mRNA abundance in equine uterine endometrium. Domest Anim Endocrinol 16: 183-192. 
24. Corah LR (1988) Nutrition of beef cows for optimizing reproductive efficiency. Compendium of Continuing Education 10(5): 695.

25. Delma K (2012) Sheep Reproduction Basics and Conception Rates.
26. Ferguson JD and Chalupa W (1989) Impact of protein nutrition on reproduction in dairy cows. J Dairy Sci 742: 746.

27. Grant W, Montgomery S, Galloway M, Davis GH, Mcnatty KP (2001) Genes controlling ovulation rate in sheep. Reproduction 121: 843-852.

\section{Your next submission with Juniper Publishers will reach you the below assets}

- Quality Editorial service

- Swift Peer Review

- Reprints availability

- E-prints Service

- Manuscript Podcast for convenient understanding

- Global attainment for your research

- Manuscript accessibility in different formats

( Pdf, E-pub, Full Text, Audio)

- Unceasing customer service

Track the below URL for one-step submission https://juniperpublishers.com/online-submission.php 